\title{
BOS LAUNCHES NEW GUIDE TO EMPOWER ADULT PATIENTS
}

On 10 May 2016 the British Orthodontic Society (BOS)

launched a new online resource to support the decision-making of the rising number of adults opting for orthodontic treatment.

The BOS Guide: Orthodontics for adults is a first for BOS in that it's designed for patients to read before they see a clinician.

There have never been so many different treatment choices for patients. Last month BOS warned against websites offering DIY orthodontic treatment because of the risk they pose, posting a statement on the BOS

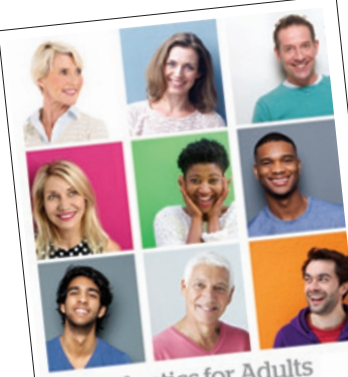
website: http:// www.bos.org. uk/News-andEvents/BOSStatementDo-ityourselfbraces. The statement strongly advises against any treatment which bypasses a consultation with an orthodontist or dentist.

The BOS Guide covers all aspects of orthodontic decision-making: why, how, where and who. Each section has key points or tips which guide the patient towards getting the information they need to make the right choice for them.

A complementary video featuring Professor Tim Newton, Professor of Psychology as applied to Dentistry, contains advice on the questions to ask a clinician.

Alison Murray, President of BOS, said at the press launch for the new guide: 'We want to ensure that individuals are empowered to understand the choices they are making.

'We really want the guide to adult orthodontics to give potential patients the full picture and to highlight that orthodontic treatment can be complex. Our aim is to provide information which will help adults wanting treatment to become more discriminating consumers.'

The guide can be found at www.bos.org.uk/adultorthodontics.
POSTDOC IRINA WILL TAKE PLAQUE

TO THE PEOPLE

Irina Velsko,

a postdoctoral research associate at the University of Oxford working on ancient dental calculus, has been selected to present at the Soapbox Science Oxford public outreach event in June, talking about how oral health and oral microbes affect systemic health.

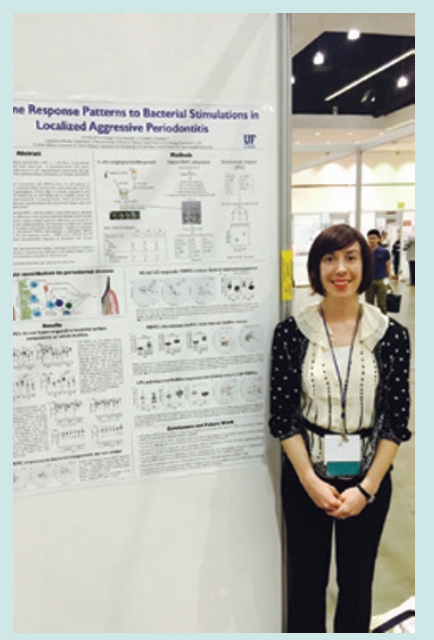

Soapbox Science aim to "bring science to the people', promoting women scientists and transforming public areas into an arena for public learning and scientific debate. Irina's talk on Cornmarket Street in Oxford will encourage the public to learn about why oral health is so important, in an easily accessible, interactive environment.

Further details can be found at: http://soapboxscience.org/?page_id=2745.

Irina is pictured at the American Association for Dental Research (AADR) annual meeting in March this year.

\section{BOOK REVIEW}

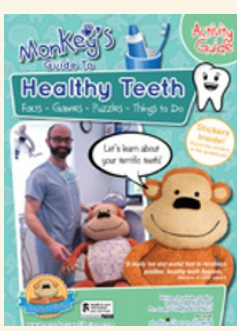

MONKEY'S GUIDE TO HEALTHY TEETH

Helen Sadler

Pack price (for both

Monkey's Guide To Healthy Teeth and Monkey's Family Visits the Dentist) $£ 5.50$ ISBN 9781909479166 and 9781909479159

This book comes with an activity guide, a Monkey puppet and an online resource. The 'Monkey's Guide' evolved due to the author, Helen Sadler, having an 18-monthold daughter who faced major surgery. As a family, they felt extremely anxious and so they made a homemade storybook - the theme of 'Monkey's Guide' was born. There are many other titles in the guide for various procedures or hospital visits.

I would say the book is more of a magazine, entitled Monkey's Family Visits the Dentist with 18 colourful pages showing real time photographs on every page. It is a very realistic journey with Monkey and his sister Josephine and Dad (who are not monkeys) who travel to a dental practice for a check-up with a dentist. A variety of photographs capture the various stages involved in an appointment with the dentist. The combination of products given with this pack, including colouring pencils and stickers, make learning fun and interactive, alleviating any fears. The online resource is particularly helpful if any further information is needed.

This dental aid looks like it is targeted at young children around the age of $5-7$, although a specific age range is not given. Families can read this or complete the activity guide together, which has lots of hidden dental facts throughout, along with stickers and a 'Terrific Teeth Cleaning Chart'. The real-life photographs of decayed teeth and the diet advice are particularly good. The Monkey puppet that comes with the pack would, I imagine, provoke fun in what could be a potentially daunting procedure for a child. The Monkey puppet could also be transported with the child to any hospital or dental visit and if there is a range of books in this series, the monkey could be interchanged among them.

As with any book, there are potential negatives. The photographs including the dentist show his dental mask to be untied. This would not meet infection control standards that are emphasised to the dental profession. As far as the child lying on the dental chair, the position shown could be seen as incorrect; paediatric standards ensure the child's hands are kept around the area of the stomach or by a child's side to ensure safety to the dentist and child.

However, the overall impression for this interactive guide has been very well thought out, combining interaction and education. The variety of apparatus aids the child in having fun and associating a visit to the dentist in a non-threatening manner. I would recommend this to families with young children or multiple children who visit the dentist.

C. LYTTLE 